\title{
Los espacios para la acción. Intersticios y tramas en la construcción del relato en la Microhistoria y el Marxismo Británico*
}

\begin{abstract}
Resumen
Este artículo pretende contribuir a la discusión en torno a la problemática sobre la construcción del relato en la historiografía. Al retomar el debate sobre el equilibrio entre la narrativa y las pruebas documentales se analiza un contexto de transformación disciplinar y las implicaciones que en ello tuvo la discusión sobre la escritura de la historia planteada por autores ampliamente reconocidos. Acercar la propuesta de dos tradiciones académicas que han sido puntos de referencia en décadas recientes, tanto por sus innovaciones metodológicas como por su estilo narrativo, se nos muestra ya no como el análisis de experiencias aisladas sino como un intento de respuesta a cuestiones disciplinares fundamentales en los estudios históricos.
\end{abstract}

Palabras clave: Marxismo Británico, historiografía, relato, narrativa, microhistoria.

Referencia para citar este artículo: LARGO VARGAS, Joan Manuel (2017). "Los espacios para la acción. Intersticios y tramas en la construcción del relato en la Microhistoria y el Marxismo Británico". En Anuario de Historia Regional y de las Fronteras. 22 (2). pp. 143-163.

Fecha de recepción: 12/07/2016

Fecha de aceptación: 15/11/2016

\begin{abstract}
Joan Manuel Largo Vargas: Estudiante de Maestría en Historia, Universidad Nacional de Colombia-sede Medellín. Historiador, Universidad del Valle, Colombia. Historiador del Grupo de Apoyo de la Dirección Académica, Universidad Nacional de Colombia-sede Medellín, Colombia. Docente de cátedra de la Facultad de Comunicación Audiovisual del Politécnico Colombiano Jaime Isaza Cadavid (2015-2016), Colombia. Docente de cátedra del Departamento de Organización y Gerencia de la Universidad Eafit (2015-actual), Colombia. Correo electrónico: jmlargov@unal.edu.co. Código ORCID: 0000-0001-5937-9586.
\end{abstract}

\footnotetext{
*Este artículo se sustenta en la reflexión teórica llevada a cabo en las asignaturas obligatorias de la Maestría en Historia de la Universidad Nacional de Colombia-Sede Medellín, Colombia, de la cual soy estudiante. Indirectamente, esta reflexión sirvió a mi proyecto de tesis El liberalismo reaccionario. Imaginarios sociales y lenguajes políticos en Colombia, 1930-1953, y con el aval del grupo de investigación Prácticas, saberes y representaciones en Iberoamérica, clasificado en categoría B por Colciencias.
} 


\title{
Spaces for Action. Interstitices and Plot in the Construction of the Story in the Microhistory and British Marxism
}

\begin{abstract}
This article wants to contribute to the discussion about the construction of story in the discipline of historiography. We check a context of discipline transformation and return to debate of balance between the narrative and the documental proofs, also think in the postulates of recognized authors about the History writing. Finally, we think that the nearness between two academic traditions that have become reference points in recent years, thanks to their methodological innovations and narrative style, gives a comprehension more generous of the same, not like isolated experiences, but as transcendental answers to fundamental questions in contemporary historic studies.
\end{abstract}

Keywords: British Marxism, Historiography, Story, Narrative, Microhistory.

\section{Espaços para ação. Interstícios e tramas na construção do relato em Micro- história e Marxismo britânico}

\begin{abstract}
Resumo
Este artigo pretende contribuir para a discussão sobre a problemática da construção do relato na disciplina da historiografia. Ao retomar o debate sobre o equilíbrio entre a narrativa e as provas documentais, se analisa um contexto de transformação disciplinar e as implicações que a discussão sobre a escritura da historia planteada por autores amplamente reconhecidos teve neste contexto. Aproximar a proposta de duas tradições acadêmicas que tem sido pontos de referencia em décadas recentes, tanto por suas inovações metodológicas como por seu estilo narrativo, nos revela não a análise de experiências isoladas senão uma tentativa de resposta a questões disciplinares fundamentais nos estudos históricos.
\end{abstract}

Palavras-chave: Marxismo británico, historiografia, história, narrativa, microhistória. 


\section{Introducción}

Después de la Segunda Guerra Mundial, buena parte de los paradigmas de la historiografía occidental se centraron en tres modelos básicamente: el Marxismo, la Escuela de Annales y la Historia Económica. Hasta la década de 1970 la disciplina histórica había alcanzado un alto nivel de credibilidad, puesto que los trabajos entonces realizados lograron poner en diálogo a los historiadores profesionales con las principales exigencias de los postulados del estructuralismo ${ }^{1}$. Este panorama se va a transformar en las décadas de 1970 y 1980, período durante el cual, desde diferentes contextos, los historiadores van a sentar una postura crítica frente a lo que había sido el oficio hasta ese entonces.

Los cuestionamientos que hicieron parte de esta renovación de la historiografía podrían clasificarse en dos grandes grupos. En primer lugar, aquellos que hacían referencia a la transformación del estatuto científico de la historiografía, esto es, la relación con el relativismo y las propuestas de un denominado posmodernismo. Aquí podemos ubicar la reivindicación de lo singular frente a las generalidades (o la ruptura de los grandes meta-relatos) y el abandono de la búsqueda objetiva de la verdad histórica o el rechazo a las visiones totalizantes y absolutas sobre un determinado proceso histórico. Estos cuestionamientos de orden teórico, en la medida en que buscaban apartarse de la tradicional ciencia estructuralista de los años cincuenta y sesenta, trajeron consigo una serie de cuestiones metodológicas, tales como la vuelta al lenguaje entendido como factor determinante de interpretación, la preferencia por lo particular y excepcional antes que por lo regular y constante, y la narración como herramienta fundamental del conocimiento histórico ${ }^{2}$. En segundo lugar, los cuestionamientos del orden de lo temático, donde aparecerían los diversos contenidos de aquellas nuevas orientaciones e intereses que los historiadores introdujeron en su trabajo. Por ejemplo, el estudio de sectores diferentes a las élites tradicionales, tales como los grupos sub-alternos, y que incluso empezaban a reconocerse con cierta capacidad de participación en los procesos históricos. En el mismo sentido podría notarse un distanciamiento de los temas socio-económicos, o una reestructuración del pensamiento de los mismos, así como una reapropiación de los temas de tipo cultural. Esa transformación de la visión del conocimiento científico, antes mencionada, influyó en el desplazamiento que los contenidos de la historiografía harían desde el estudio de las estructuras sociales y los fenómenos seriales, hacia nuevos actores y hacia procesos de índole menos económica o sociológica, tales como las mentalidades colectivas ${ }^{3}$. Así mismo la vuelta del sujeto, cuyo planteamiento tomaría fuerza desde la filosofía francesa posestructuralista,

\footnotetext{
${ }^{1}$ A través de la cuantificación, la construcción de series, y el tratamiento estadístico, la disciplina que ascendía en los años sesenta buscaba formular las relaciones estructurales, lo que Ginzburg denominaría paradigma galileano: Chartier, Roger. "La historia, entre relato y conocimiento", en Historia y Espacio, núm. 17, 2001, pp. 185-206.

${ }^{2}$ Aróstegui, Julio. "La renovación contemporánea de la historiografía", en Aróstegui, Julio, La Investigación Histórica: Teoría y Método (Madrid: Crítica, 1995), pp. 96-148.

${ }^{3}$ Aurell, Jaume. "La transición de los setentas: de las economías a las mentalidades", en Aurell, Jaume, La escritura de la memoria: de los positivismos a los posmodernismos (Valencia: Universitat de Valencia, 2005), pp. 87-112. Aróstegui, Julio, Op Cit.
} 
Los espacios para la acción. Intersticios y tramas en la construcción del relato...

impulsaba la elección de unas temáticas más acordes con lo cultural, cuyo tratamiento implicaría cada vez menos el uso de las antiguas herramientas de las ciencias sociales ${ }^{4}$.

Finalmente, habría que recordar que estos cuestionamientos sucedieron a la par que se producía un cambio de las relaciones interdisciplinares de la Historia. Si bien antes de la década del 70 eran la Economía y la Sociología las disciplinas que más dialogaban con la historiografía ${ }^{5}$, ahora eran la crítica literaria y la antropología las que aportaban herramientas de análisis a los historiadores de las nuevas generaciones. El contexto político tampoco es menos importante; por un lado la radicalización de las izquierdas empezó a ceder con el desmoronamiento de la URSS, por el otro, el cuestionamiento a las ideas del progreso y la modernidad, antes casi incuestionables, cimentó nuevas posturas frente al quehacer del historiador. Así las cosas, la disciplina histórica del último cuarto del siglo XX no podía parecerse demasiado a la de sus predecesores. Dos casos paradigmáticos de esa transición disciplinar que señalamos, aparecen configurados en las dos escuelas o modelos historiográficos de la Microhistoria italiana -en cabeza de autores como Carlo Ginzburg y Giovanni Levi-y el Marxismo británico -cuyas figuras más representativas pueden observarse en Eric Hobsbawm y Edward Thompson-. Nuestro acercamiento no constituye un análisis exhaustivo sobre la interpretación histórica desde el punto de vista narrativo o literario, sino que se limita a observar con mayor profundidad los lineamientos de estas dos escuelas historiográficas, muy definidas, y la obra de un grupo selecto de historiadores dentro de esos dos marcos. Los criterios de tal selección no son, en absoluto, arbitrarios; corresponden al interés marcado de los historiadores contemporáneos, en términos generales, $\mathrm{y}$, de modo particular, para el caso colombiano, la relevancia que estos enfoques han representado la generación a su vez artículos y entrevistas de reciente factura ${ }^{6}$.

Se le ha denominado giro narrativo a uno de los rasgos fundamentales que caracterizó la renovación de la historiografía en la segunda mitad del siglo XX. Como giro narrativo se ha designado la tendencia de los historiadores de las décadas de $1970 \mathrm{y}$ 1980 a privilegiar, en la expresión de los resultados de sus trabajos de investigación, el uso de herramientas más sencillas o cercanas a la literatura, soslayando, de alguna manera, las anteriores escrituras descriptivas y analíticas del estilo estructuralista?

\footnotetext{
${ }^{4}$ Como afirma Carlos Barros: “[...] el desinterés por la historia económico-social tiene como telón de fondo la presión de una demanda cultural y vital más individualista que reclama una historia más subjetiva”. Barrios, Carlos. "La contribución de los Annales y la historia de las mentalidades. 1969-1989", en Iztapalapa, Revista de Ciencias Sociales y Humanas, núm. 36, México, Universidad Autónoma Metropolitana, 1995, pp. 73-102.

${ }^{5}$ Febvre, Lucien. Combates por la historia (Barcelona: Ariel, 1974); Braudel, Fernand. La historia y las ciencias sociales (Madrid: Alianza Editorial, 1970).

${ }^{6}$ A modo de ejemplos se presentan: la entrevista a Giovanni Levi publicada en Historia Crítica; el reciente artículo de la profesora María Eugenia Chaves: Chaves, María Eugenia. "La pregunta y el indicio. A propósito del trabajo sobre fuentes judiciales y casos particulares en la investigación histórica sobre los sectores subalternos", en Almario Oscar (ed.), Las fuentes en las reflexiones sobre el pasado: usos y contextos en la investigación histórica en Colombia (Medellín: Universidad Nacional de Colombia, 2014), pp. 143-158; así como el dossier coordinado por ella misma en la revista Historia y Sociedad: Chaves, María Eugenia. "Presentación. Reflexiones sobre la Microhistoria italiana: conceptos, método y estudio de casos", en Historia y Sociedad, núm. 30, Universidad Nacional de Colombia-sede Medellín, 2016, pp. 17-20.

${ }^{7}$ Aurell, Jaume. "El giro narrativo", en Aurell, Jaume, La escritura de la memoria: de los positivismos a los posmodernismos (Valencia: Universitat de Valencia, 2005), pp. 131-147.
} 
Sin embargo hay que recordar que, desde la antigüedad, la historia ha estado profundamente relacionada con la narración; por lo que su lugar como relato y escritura no puede ser cuestionado $^{8}$. Eric Hobsbawm, en su intercambio de opiniones con Lawrence Stone, proponía observar la ampliación del campo historiográfico -las dificultades técnicas en la presentación de un relato que pretendía analizar un amplísimo rango de actividades y pensamientos humanos-, y sus consecuentes novedades, más como la continuación de los esfuerzos de varios historiadores, que no como una ruptura o un rechazo total hacia el pasado 9 . Lo problemático del notable giro o retorno hacia la narrativa es la perspectiva, criticada por Carlo Ginzburg, que encabezaría Hayden White, y que postularía, siguiendo las críticas del historiador italiano, una reducción de la tarea del historiador a la elaboración de discursos o usos estéticos del lenguaje. Este problema suscitó los síntomas de crisis que invadirían a la historiografía de los años ochenta, viéndose esta reducida a la elaboración de meras ficciones. Serían Ginzburg y Michel de Certeau quienes de manera más notable enfrentarían el problema; el primero desde la elaboración de un reconocido trabajo histórico y la propuesta de una novedosa metodología, y el segundo desde una reflexión profunda sobre las dimensiones contextuales de la escritura de la historia ${ }^{10}$.

Como ya se ha dicho, la evolución de la disciplina en las décadas finales del siglo $\mathrm{XX}$ introdujo una postura distinta frente al papel de la historiografía como ciencia, específicamente puede hablarse de la crítica a la tradicional manera de exponer los resultados de la investigación. Pero no fue solamente ese factor el que determinó el retorno a la narrativa; además se buscaba una renovación metodológica, dado que la demanda de conocimiento del pasado ponía de presente unas inquietudes distantes a las de períodos anteriores. Si los temas estudiados se apartaban progresivamente de los problemas estructuralistas, y ello a su vez demandaba un uso diferenciado de fuentes documentales, las fórmulas narrativas se erigían como poderosas herramientas metodológicas, que vivificaban las explicaciones ${ }^{11}$. Otro elemento importante para la vuelta a la narrativa fue el papel de la memoria y sus relaciones con la historia; según Chartier, el desarrollo que para finales del siglo XX tuvo la discusión de autores como Maurice Halbawchs y Pierre Nora se dejó sentir dentro de la evolución de algunos historiadores. La consciencia del papel que los relatos, históricos o no, juegan dentro de la constitución de las memorias colectivas, y el convencimiento de la diferencia entre historia y memoria, llevó a reflexiones como la realizada por Michel de Certeau, en las que el papel del contexto y las sociedades en las que se enmarcan los historiadores y sus obras, y la creciente necesidad de tomar en cuenta los elementos que determinan en parte la construcción de un trabajo historiográfico, redireccionaron los intentos de renovar la disciplina histórica ${ }^{12}$.

\footnotetext{
${ }^{8}$ Chartier, Roger. La historia o la lectura del tiempo (Barcelona: Editorial Gedisa, 2007), p. 21.

${ }^{9}$ Hobsbawm, Eric. “The Revival of Narrative: Some Comments”, en Past \& Present, núm. 86, Oxford, 1980, pp. 3-8.

${ }^{10}$ Chartier, Roger, Op Cit., pp. 23 y 27; Chartier, Roger. "La historia, entre relato y conocimiento", en Historia y Espacio, núm. 17, Cali, Universidad del Valle, 2001, pp. 185-206, y De Certeau, Michel. La escritura de la historia (México: Universidad Iberoamericana, 1999).

${ }^{11}$ Habría un desplazamiento desde las estructuras y los mecanismos hacia las racionalidades y las estrategias: Chartier, Roger. "La historia, entre relato y conocimiento"..., p. 188.

${ }^{12}$ Chartier, Roger. “La historia, entre relato y conocimiento”..., pp. 38 y ss.
} 


\section{Una nueva trama para la historia}

Las anteriores anotaciones son un buen punto de partida para analizar la relación que existe entre dos figuras fundamentales en los estudios históricos contemporáneos; Hayden White y Carlo Ginzburg, quienes, no obstante la peculiar discusión que parece existir entre ambos, van a coincidir, a fin de cuentas, en un punto esencial. En los años ochenta el historiador italiano va a plantearse el tema de la relación entre verdad y escritura histórica, tomando como interlocutor ya no a Michel Foucault, sino al autor norteamericano de Metahistory ${ }^{13}$. Ginzburg va a proponer que White escribe desde la peligrosa aventura intelectual, que constituye el escepticismo epistemológico en la historiografía; los vestigios del pasado, a la luz de esa peligrosa aventura, no serían más que representaciones desde las cuales es incognoscible el pasado ${ }^{14}$. Esta discusión, particular en la medida en que no se conocen respuestas directas de uno de los contendores, va a revelar, en últimas, la cercanía de las dos posturas.

Hayden White ha propuesto, como uno de sus objetivos, develar las relaciones existentes entre la producción literaria y la operación historiográfica, por lo que parte del estatus de la narrativa histórica como artefacto verbal ajeno a las formas de verificación y experimentación tradicionales en las ciencias, lo que considera una carencia vital en las reflexiones de la filosofía de la historia ${ }^{15}$. White busca establecer la relación entre conciencia mítica y conciencia histórica, para esto se apoya en la postura de Northrop Frye, quien señalaba la distancia singular existente entre lo histórico y lo mítico; así la escritura histórica sería un escrito discursivo que al asumir el elemento ficcional se convierte en un género bastardo, unión de historia y poesía ${ }^{16}$. Es a partir de esta reflexión, en torno a los elementos ficcionales en el relato histórico, que el norteamericano introduce la noción de tramado, que se refiere a cómo se codifican los hechos en tipos específicos de estilo o estructuras de trama. Según White las situaciones históricas no poseen significados intrínsecos, y es por ello que el historiador puede plantearlas en unos estilos o tramados cómicos, trágicos o irónicos; los mismos hacen parte de la herencia cultural y permitirían comprender aquello que de entrada es extraño por hacer parte del pasado. La labor del historiador va a ser, entonces, siguiendo los planteamientos del autor norteamericano, análoga a una operación literaria, que a la vez figura como productora de ficción $n^{17}$.

\footnotetext{
${ }^{13}$ Serna, Justo y Pons, Anaclet. “Anti White”, en Serna, Justo y Pons, Anaclet. Cómo se escribe la microhistoria. Ensayo sobre Carlo Ginzburg (Madrid: Cátedra-Universitat de València-Frónesis, 2000), http://www.uv.es/jserna/AntiWhite.htm (10 de agosto del 2014).

14 Ibid.

${ }^{15}$ White, Hayden. "El texto histórico como artefacto literario", en White, Hayden. El texto histórico como artefacto literario (Barcelona: Paidós, 2003), pp. 107-139; White, Hayden. "La poética de la historia", en White, Hayden, Metahistoria: La imaginación histórica en la Europa del siglo XIX (México: Fondo de Cultura Económica, 2000), pp. 9-50.

${ }^{16}$ Ibid., pp. 110 y 111.

${ }^{17}$ Ibíd., p. 115. Vale la pena aclarar que el sentido de ficción de White no es peyorativo; se puede afirmar, como ha apuntado Verónica Tozzi, que el hilo conductor de la obra del norteamericano es "[...] su preocupación por recordarnos que nuestra vinculación con el pasado es, y no debe dejar de ser, emotiva": Tozzi, Verónica. "Introducción”, en White, Hayden, El texto histórico como artefacto literario (Barcelona: Paidós, 2003), p. 10.
} 
Para White una de las maneras de dar sentido a los acontecimientos es codificarlos bajo formas de relato, definidas por las estructuras pre-genéricas de trama: esa codificación nos familiariza con lo no familiar, pues el pasado siempre se muestra con rasgos extraños o exóticos. Esas estructuras, tan impersonales como las profundidades del conocimiento mítico, y con las cuales los historiadores logran refamiliarizar el pasado, nos llevarían a pensar en las narrativas históricas como enunciados metafóricos, que en su aspecto mimético no pueden ser observadas como un modelo a escala que se compara con un original, sino como un conjunto de imágenes. De éste último punto, siguiendo la propuesta de White, es desde donde se entendería que el conocimiento histórico avanza como la literatura: a partir de trabajos clásicos, que en su posibilidad de mímesis resultan invalidables en términos propiamente científicos. Ajena a métodos de verificación, como los de las ciencias naturales, la eficacia de labor del historiador dependería así, exclusivamente, de su tacto para escoger y desarrollar un tramado de hechos.

Ha sido precisamente esta perspectiva la que ha generado el malestar expresado por Carlo Ginzburg, quien a su vez desemboca en la reafirmación de la proximidad existente entre el arte y la producción del relato histórico, y que podría leerse como una toma de distancia frente al esquema tradicional de la historiografía científica. En este punto, es necesario recordar las ideas de Eric Hobsbawm alrededor del revival de la narrativa: los esfuerzos renovadores en los trabajos históricos, antes que un rechazo al pasado, constituyen la expresión de la dificultad de síntesis, articulación y divulgación de una historiografía que en la segunda mitad del siglo pasado ha complejizado su campo y ampliado sus expectativas ${ }^{18}$. Entonces, así como la metáfora no refleja una cosa en sí, sino que brinda apenas la dirección hacia un conjunto de imágenes ${ }^{19}$, los trabajos de un historiador constituyen signos no unívocos ni exactos, que asemejan los acontecimientos relatados a formas profundas de nuestra cultura literaria: lejos de la precisión y la noción de verdad aparentemente incuestionable de las ciencias naturales, el relato histórico aparecería más cercano a los ejercicios de interpretación, y por eso mismo cercanos al arte ${ }^{20}$.

La labor de quien escribe la Historia, para Hayden White, no va a ser otra distinta a la de cargar los acontecimientos con "[...] la significatividad simbólica de una estructura de trama comprensible"21. Ahora bien, el interlocutor italiano de White, aun cuando intenta establecer la mayor distancia posible de lo sostenido por el norteamericano,

\footnotetext{
${ }^{18}$ Hobsbawm, Eric, Op Cit.

19 Para White las narrativas históricas no serán solamente modelos, “[...] sino también enunciados metafóricos que sugieren una relación de similitud entre dichos acontecimientos y procesos y los tipos de relato que convencionalmente usamos [...]". White, Hayden, Op Cit., p. 120.

${ }^{20}$ Tempranamente Marc Bloch daría cuenta de esa certeza del carácter incompleto de la interpretación del historiador; haciendo el rescate de Coulanges y Michelet dice que tales autores eran lo suficientemente grandes para no creer que la sociedad fuera un rompecabezas mecánicamente ajustado y afirma: "[...] el conocimiento de los fragmentos estudiados sucesivamente, cada uno de por sí, no dará jamás el del conjunto; no dará siquiera el de los fragmentos mismos": Bloch, Marc. Introducción a la Historia (México: Fondo de Cultura Económica, 1979), p. 120.

${ }^{21}$ White, Hayden, Op Cit., p. 126.
} 
termina por coincidir en varios aspectos con su propuesta. Por ejemplo, cuando el autor norteamericano retoma la idea de imaginación constructiva de Collingwood, termina recogiendo la analogía entre historiador y detective, que pone de manifiesto la capacidad del primero para elaborar relatos plausibles mediante cúmulos de hechos. Justo Serna y Anaclet Pons han mostrado que Ginzburg, al tomar a Hayden White como interlocutor o contrincante, acudiría a los trabajos de Arnaldo Momigliano, en los cuales es visible el uso de la analogía entre médico e historiador para probar que las verdades de los historiadores, aunque también requieren artificios de presentación y persuasión, constituyen datos objetivos ${ }^{22}$. Vale la pena entonces subrayar el hecho de que White, al recoger estas analogías del oficio del historiador, antes que apuntar a un escepticismo epistemológico, subraya la importancia de la imaginación en la construcción de las narrativas históricas.

Pero en lo que definitivamente se encuentran las posturas de White y Ginzburg es en la necesidad de actualizar la pregunta por la escritura de la historia y su relación con la literatura o las estrategias narrativas ${ }^{23}$. Ginzburg, al optar por una perspectiva que privilegia el análisis microscópico, estaría tomando en cuenta la propuesta de un literato: Raymond Queneau, quien con sus ejercicios de estilo llamaría la atención sobre los detalles menudos y los personajes pequeños frente a los grandes y los poderosos ${ }^{24}$. De este modo, la perspectiva detallista adoptada por Ginzburg establecería un diálogo con la literatura en su distanciamiento de los modelos macroscópicos y cuantitativos $^{25}$. Por otra parte, la narrativa histórica, ante los ojos de White, muestra un carácter errático (en el mejor sentido de la palabra) o aproximativo, pues si se trata de una estructura metafórica que no refleja propiamente las cosas que señala, sino que más bien nos indica un conjunto de imágenes para entender lo que se indica, tenemos entonces un proceder fragmentario, provisional, abierto a suposiciones, intuiciones e indicios. $\mathrm{Y}$ es en este nivel que pueden señalarse ciertas coincidencias con Ginzburg, cuando este último nos señala que la realidad es porosa y discontinua y por ello exige un movimiento alternativo entre lo macro y lo micro, a la vez que implica un acercamiento intuitivo e indiciario ${ }^{26}$. El mismo Ginzburg ha propuesto que en su trabajo de El Queso y los gusanos se buscaba reconstruir el mundo intelectual y moral de Menocchio, un molinero del siglo XVI, a través de la documentación de quienes lo llevaron a la hoguera, esfuerzo que desembocaría en "[...] un relato que

\footnotetext{
${ }^{22}$ Serna, Justo y Pons, Anaclet, Op Cit.

${ }^{23}$ Para Chartier uno de los elementos característicos de la ruptura de las certezas de la disciplina a finales de la década de 1980, va a ser "[...] la toma de conciencia por parte de los historiadores de que su discurso, cualesquiera que sea su forma es siempre un relato". Chartier, Roger, Op Cit., p. 190.

${ }^{24}$ Ginzburg, Carlo. "Microhistoria dos o tres cosas que sé de ella", en Ginzburg, Carlo. El Hilo y las Huellas: Lo verdadero, lo falso, lo ficticio (Buenos Aires: Fondo de Cultura Económica, 2010), pp. 351394.

${ }^{25}$ En el llamado de atención de Hobsbawm sobre la reconsideración de un supuesto revival de lo narrativo, es interesante recordar que Marc Bloch también advirtió este problema al reconocer que debido a la delicadeza que exigía la traducción de los hechos humanos, para su puesta en práctica "[...] se necesita una gran finura del lenguaje, un color adecuado en el tono verbal": Bloch, Marc, Op Cit., p. 25.

${ }^{26}$ Ginzburg, Carlo. "Huellas. Raíces de un paradigma indiciario", en Ginzburg, Carlo, Tentativas (Morelia: Universidad Michoacana de San Nicolás de Hidalgo, 2003), pp. 93-155.
} 
transformase las lagunas de la documentación en una superficie lisa"27; lo que a su vez respondía al cuestionamiento de la figura del "historiador-narrador omnisciente" 28 . Si para White el texto histórico alude a signos ambiguos, estructuras simbólicas o metáforas extendidas, podemos leer en ese esfuerzo una alternativa para refrendar la posibilidad de conocimiento en la historia, y ello se podría vincular fácilmente a las estrategias narrativas empleadas por Ginzburg, en las que la búsqueda de la verdad -hipótesis, dudas e incertidumbres-aparecían en el relato, convirtiendo los límites en un elemento narrativo ${ }^{29}$.

Ginzburg, sin embargo, ha tenido en cuenta más elementos a la hora de enfrentar la problemática de la escritura histórica. Para ello, por ejemplo, se ha acercado a la retórica aristotélica, señalando que esta halla su sustento esencial en la prueba, y no se agota en los adornos del discurso ${ }^{30}$. El historiador entonces, si seguimos a Ginzburg, no siempre trabaja con evidencias irrefutables, sino que la mayoría de las veces lo hace con entimemas que crean un efecto de verosimilitud ${ }^{31}$. Lo que subyace bajo esta última argumentación, es la tensión existente entre una Historia anticuaria y una Historia testimonial; desde los antiguos griegos se nota una contraposición entre una Historia que busca partir de evidencias físicas y, por otra parte, una Historia fundada en la palabra a través de testimonios orales y documentales ${ }^{32}$. Ginzburg realiza paralelos analíticos entre la literatura y pintura realistas y la escritura histórica; lo particular y sugestivo de este planteamiento es que aún desde ese carácter verbal y ficcional, va a ser el manejo de la prueba el nervio vital de la Historia ${ }^{33}$. Así las cosas, las coincidencias con una visión de la historia cercana al arte son matizadas y redimensionadas: "Términos como ficción y posibilidades no deben llamar a engaño. La cuestión de la prueba sigue estando, más que nunca, en el centro de la investigación histórica; pero su estatuto es modificado de forma inevitable cuando se afrontan temas diferentes a los de épocas pasadas, con la ayuda de una documentación también diferente" 34 . En esta propuesta, podríamos afirmar, se avanza unos pasos más que en la de White, en la medida en que se recupera la cuestión de las evidencias o las pruebas como la posibilidad de un conocimiento efectivo del pasado, sin embargo

\footnotetext{
${ }^{27}$ Ginzburg, Carlo. "Microhistoria dos o tres cosas que sé de ella", Op Cit., pp. 373 y 374.

${ }^{28}$ Ibid.

${ }^{29}$ Ibid., p. 382.

${ }^{30}$ Ginzburg, Carlo. "Historia, retórica, prueba. Sobre Aristóteles y la historia hoy", en Entrepasados, núm. 27, Buenos Aires, Universidad de Buenos Aires, 2005, pp. 153-166.

${ }^{31}$ Quintiliano, Cicerón y otro autor anónimo, casi coinciden en la cuestión de poner los hechos ante los ojos, es a eso a lo que aludía la demonstratio, palabra que en las lenguas europeas modernas ha perdido su carga retórica, pues esta “[...] hacía referencia al gesto del orador que señalaba un objeto invisible, volviéndolo casi palpable -enargés- para quien lo oía, gracias al poder casi mágico de sus propias palabras". Ginzburg establece diferencias entre enargeia, a través de la descripción, y la autoridad de la cita, que se aparta, en cierta medida, de la fuerza creadora del lenguaje: Ginzburg, Carlo. "Descripción y Cita", en Ginzburg, Carlo, El Hilo y las Huellas: Lo verdadero, lo falso, lo ficticio (Buenos Aires: Fondo de Cultura Económica, 2010), p. 25.

${ }^{32}$ Ibid., pp. 19-54.

${ }^{33}$ Ginzburg, Carlo. “Apéndice. Pruebas y posibilidades”, en Ginzburg, Carlo, El Hilo y las Huellas: Lo verdadero, lo falso, lo ficticio (Buenos Aires: Fondo de Cultura Económica, 2010), pp. 433-465.

${ }^{34}$ Ibid., p. 463.
} 
Los espacios para la acción. Intersticios y tramas en la construcción del relato...

hay que señalar que tampoco es cierto que el autor de Metahistory niegue del todo la realidad del conocimiento del pasado, como ciertas interpretaciones lo plantean.

Al acercarse a la literatura contemporánea, Carlo Ginzburg va a introducir la capacidad del historiador de acercarse a las experiencias desde un análisis detallista o microscópico, pero no por ello nos encontramos frente a una mera cuestión de estética ${ }^{35}$. En la renovada y artesanal escritura del relato histórico que se construyó desde la microhistoria italiana es que reside, en buena parte, la posibilidad de observar los lugares para la acción de los seres humanos, en cuanto las acciones antes descuidadas por una visión demasiado amplia emergen frente a la perspectiva del microanálisis, y en la medida en que el reconocimiento de las lagunas en la documentación y las incertidumbres del autor, ponen de presente la necesidad de articular las mismas en la presentación de los resultados de la investigación. En El queso y los gusanos podemos observar varios de los elementos que suscita el problema de la escritura del relato histórico y la veracidad ${ }^{36}$. En primer lugar, el asunto del cambio de perspectiva, donde al igual que en la literatura contemporánea se deja atrás a los grandes personajes y acontecimientos, para dar paso a detalles aparentemente minúsculos. Centrar el trabajo de investigación sobre las clases subalternas del pasado, en la figura de Domenico Scandella, es para Ginzburg cumplir con una de sus propuestas: la de convertir en libro aquello que desde la historia convencional no pudo haber sido más que un pie de página ${ }^{37}$. Este caso de un molinero italiano es rico en descripciones, que recuerdan la descripción que Ginzburg ofrece del recurso de la enargeia en la obra de Homero; casi que podemos palpar el pueblo de Menocchio, así como su "bata, capa y gorro de lana blanca" ${ }^{38}$. Pero eso no es lo único, lo fragmentario y lo provisional también emergen en el trabajo de Ginzburg, pues no se toma un solo camino como si una hipótesis vigorosa tuviera que ser demostrada a ultranza, sino que se recorren posibles respuestas, para llegar a esa que más se aproxima sin descartar hallazgos paralelos; así como el juez o el médico recolectan evidencias y síntomas, el historiador va buscando indicios para explicar su problema ${ }^{39}$.

Encontramos entonces una narrativa en la que las lagunas documentales son sorteadas con intuiciones e imaginación, unos elementos ficcionales agudos, pero elaborados desde una plausibilidad verificable. Un presunto caso pequeño es puesto en escena

\footnotetext{
${ }^{35} \mathrm{El}$ acercamiento a la literatura que hace Ginzburg, y sus apuntes sobre la porosidad de la realidad hacen pensar en las advertencias de Bourdieu sobre la ilusión biográfica: las transformaciones en la novela moderna, especialmente en Proust, dan cuenta de lo fragmentario de la identidad personal, de la discontinuidad de lo real: Bourdieu, Pierre. "La ilusión biográfica", en Acta Sociológica, núm. 56, México, UNAM, 2011, pp. 121-128.

${ }^{36}$ Ginzburg, Carlo. El queso y los gusanos. El cosmos según un molinero del siglo XVI (Barcelona: Muchnik Editores, 1981).

${ }^{37}$ Ginzburg, Carlo. "Microhistoria dos o tres cosas que sé de ella", p. 372.

${ }^{38}$ Ginzburg, Carlo. El queso..., p. 33.

${ }^{39}$ Ginzburg, Carlo. "Huellas. Raíces de un paradigma indiciario" y Chaves, María Eugenia. "La pregunta y el indicio. A propósito del trabajo sobre fuentes judiciales y casos particulares en la investigación histórica sobre los sectores subalternos", en Almario, Oscar (ed.) Las fuentes en las reflexiones sobre el pasado: usos y contextos en la investigación histórica en Colombia (Medellín: Universidad Nacional de Colombia 2014), pp. 143-158.
} 
con un realismo vivificante y afortunado, pero no es solo en la riqueza estética donde descansa su efectividad, sino también en un conjunto de pruebas. Los vacíos en la evidencia, que son un abismo para los jueces, aparecen con un contenido bien positivo dentro de la labor del historiador, como un campo fértil de acción: las conjeturas no van a ser simples recursos estilísticos, ni meras algarabías prosaicas, inconexas o arbitrarias; son, por el contrario, la posibilidad del investigador de avanzar, aun provisionalmente, con sus preguntas ${ }^{40}$. Podríamos, a este respecto, recordar los aportes de Giovanni Levi, quien dirá que el historiador debe escribir, exponiendo las costuras de su trabajo: “Al exponer las costuras, los rumbos que pensamos tomar pero no tomamos o las hipótesis que no desarrollamos y que en un momento pensamos serían la clave, estaríamos contrarrestando la retórica autoritaria de la historia y evidenciando las limitaciones y los potenciales de la construcción de conocimiento histórico"41. Junto a lo anterior, hay otros dos elementos fundamentales que podemos señalar para vincular los avances del principal autor de la microhistoria italiana con las trayectorias de su colega Giovanni Levi y el historiador británico Edward Thompson, ambos, quepa la aclaración, afines de diversas formas a los postulados marxistas no convencionales, es decir, no adscritos a una militancia política sino cercanos a unos planteamientos teóricos ${ }^{42}$.

En primer lugar, debe observarse el asunto de las permanencias, las características míticas o estructurales en los procesos históricos. El molinero recuperado por Ginzburg expresaba en su discurso, que amalgamaba lecturas y tradición oral, la idea del país de Cucaña o nuevo mundo, una suerte de paraíso utópico que diversas culturas han proyectado a través de la historia de la humanidad; en esta idea del país de Cucaña, al encontrar un aspecto aplicable a varias comunidades o grupos sociales del pasado, puede hacerse una relación con las propuestas estructuralistas de Claude Levi-Strauss con relación a los mitos: la búsqueda incesante de estructuras atemporales. Sin embargo el tratamiento de Ginzburg no busca establecer un arquetipo, y más bien acude a esa idea como otro rasgo provisional de su explicación; no es solo la constatación de que este rasgo repetitivo aparezca por cuestiones impersonales en los pensamientos del molinero, sino más bien qué implicaciones y qué relaciones pueden establecerse desde aquella intuición. En segundo lugar, hay que señalar la organización del relato sobre la vida y las vicisitudes del molinero, que no se desglosa mediante unidades temáticas, como se esperaría de una explicación en función del análisis científico tradicional, que introduce unas estructuras sincrónicas. Muy distante de ese tipo de exposición, Ginzburg asume cierto orden cronológico lineal, con un inicio, un nudo

\footnotetext{
${ }^{40}$ Muñoz, Santiago y Pérez, María Cristina. "Perspectivas historiográficas: entrevista con el profesor Giovanni Levi”, en Historia Crítica, núm. 40, Bogotá, Universidad de los Andes, 2010, pp. 197-204.

${ }^{41}$ Ibíd., p. 202. Otra de las expresiones de esa fragmentariedad, para Jacques LeGoff, tiene que ver con el ejercicio de las periodizaciones. LeGoff, Jacques. ¿Realmente es necesario cortar la historia en rebanadas? (México: Fondo de Cultura Económica, 2016), p. 25.

${ }^{42}$ Thompson distinguiría "[...] nítidamente entre el marxismo como sistema cerrado y una tradición proveniente de Marx de investigación y críticas abiertas": Sagliati, María Cristina. "Los debates de la historia en la posmodernidad", en Cuyo. Anuario de Filosofia Argentina y Americana, núm. 24, Mendoza, Universidad Nacional del Cuyo, 2007, p. 143; Illades, Carlos. Breve introducción al pensamiento de E. P. Thompson (México: Universidad Autónoma Metropolitana, 2008).
} 
y un desenlace más o menos claros. Entonces, esa perspectiva no es una en la que se asuman los procesos como terminados, de modo que puedan verse a cabalidad desde una división temática, sino que se presentan los acontecimientos en un orden progresivo, donde las expectativas de los actores aparecen con mucha fuerza ${ }^{43}$. Desde el primer entuerto de Menocchio, avanzamos por el fluir de su existencia hasta encontrarlo casi al final de sus días, ya convertido en "[...] un viejo: delgado, cabello blanco, barba gris tirando a blanca, vestido como siempre de molinero, ropas y gorro color gris claro"44. Y no es que se trate del uso de una estructura de trama, como bien pudiera sostener Hayden White (un ejercicio de familiarización que acude a cierto estilo narrativo - un profundo sustrato cultural literario- para restituir la significación de un hecho del pasado, y así ponerlo en coordenadas entendibles y asimilables al presente). Es que en tal modelo de exposición, creemos, se hace posible subrayar el carácter de actor histórico de los sujetos, capaces de entender y valorar su entorno, de formular proyectos, y sobre todo, de transformar su realidad en una u otra manera; se trata, en últimas, de una búsqueda de los espacios para la acción humana.

\section{Individuos o multitud: Los espacios para la acción}

Tanto los historiadores que siguieron la senda del microanálisis, como los británicos que revitalizaron el interés por la cultura popular, coinciden en su cercanía con el marxismo; cercanía, hay que insistir, para dejar de lado aquello de la militancia o pertenencia estricta, que sin duda alguna condujo a resultados distintos. Antes que adscripciones o partidismos marxistas, con la carga que tal noción tuvo hasta hace unos veinte años aproximadamente, lo que encontramos en Giovanni Levi y E. P. Thompson son apropiaciones y acercamientos a las preguntas y respuestas de Karl Marx. Y esta cercanía a los planteamientos de Marx no se reduce a la fórmula esquemática de la lucha de clases, o al menos no en el sentido de un axioma teórico incuestionable. Lo que va a ser visible de la obra de Marx en los trabajos de Thompson y Levi va a ser el énfasis puesto en los conflictos y en la capacidad de los sujetos para transformar su entorno, esto es, en la posibilidad de agencia de los individuos frente a las estructuras de dominación ${ }^{45}$.

En 1985, Levi escribió una reseña crítica del exitoso libro de Robert Darnton, La gran matanza de gatos $^{46}$. En esta reseña Levi sostenía que el trabajo de Darnton se inscribía en el debate sobre la crisis de las ciencias sociales, y que era en muchos aspectos “[...]

\footnotetext{
${ }^{43}$ No es difícil vincular esta perspectiva con las notas de Paul Ricoeur sobre la interpretación: "Lo que tiene que ser entendido no es la situación inicial del discurso, sino lo que apunta a un mundo posible", Ricoeur, Paul. Teoría de la interpretación. Discurso y excedente de sentido (México: Siglo Veintiuno Editores, 2006), p. 100.

${ }^{44}$ Ginzburg, Carlo. El queso..., p. 157.

45 "Los hombres hacen su propia historia, pero no la hacen a su libre arbitrio, bajo circunstancias elegidas por ellos mismos, sino bajo aquellas circunstancias con que se encuentran directamente, que existen y les han sido legadas por el pasado": Marx, Karl. El 18 brumario de Luis Bonaparte (Madrid: Fundación Federico Engels, 2003), p. 13.

${ }^{46}$ Darnton, Robert. La gran matanza de gatos y otros episodios en la historia de la cultura francesa (México: Fondo de Cultura Económica, 1987).
} 
la síntesis extrema de un cierto modo de imaginar la antropología de Geertz"47. Allí mismo, Levi lograba caracterizar algunos de los rasgos elementales de la hermenéutica gadameriana aplicada a la Historia, aquel debate centrado en la problemática de la interpretación, y que en ciertas versiones llega a cuestionar la posibilidad de acceder a los objetos del pasado ${ }^{48}$. El movimiento de textualización de la cultura, que haría Clifford Geertz al establecer un "autor generalizado" para los "textos", separados de su "ocasión discursiva", devendría en un contexto de referencia construido por el mismo investigador". Este contexto en Darnton se va a tornar "rígido como un fondo inmóvil" 50 . Estaríamos entonces frente a un círculo vicioso, afirma Levi, "el texto" restituido por el etnógrafo para su interpretación permite evidenciar prejuicios y descubrir el mundo significativo de "el otro" en una lógica hermenéutica, pero su contexto se da desde el principio y no cambia al final: "[...] la unicidad de un texto puede tal vez proveer una mayor comprensibilidad del contexto pero no cambiar sustancialmente sus elementos" ${ }^{" 51}$. Esa circularidad nos lleva a subrayar un elemento que para Levi resulta esencial: su entendimiento del contexto y de los casos que allí aparecen como excepcionales. Es inevitable pensar en el postulado de excepcionalnormal construido por los autores de la microhistoria; aquel oxímoron que implica reacomodar el contexto para que un caso aparentemente inextricable y oscuro se pueda captar como normal ${ }^{52}$.

Un problema para Levi va a ser, entonces, la pérdida de sentido de lo relevante. Los pequeños episodios - como los estudiados por Darnton-pueden dar cuenta de actitudes culturales importantes, pero la hermenéutica como fin en sí misma -postulada por Gadamer y utilizada por Darnton- adolecería de una carencia de criterios generales de verdad y relevancia. Según este autor, esto último es lo que hace que a veces se reconozcan detalles o acontecimientos breves como supuestamente importantes, pero por una vía distinta: solo hay que insertarlos y leerlos en un contexto producido a priori, lo que se traduce en algo fatal: "[...] la investigación no agrega nada a lo ya conocido, lo confirma débilmente y de manera superflua" ${ }^{\prime 3}$. Pero para entender

\footnotetext{
${ }^{47}$ Levi, Giovanni. "Los peligros del geertzismo", en Hourcade, Eduardo; Godoy, Cristina y Botalla, Horacio. Luz y Contraluz de una Historia Antropológica (Buenos Aires: Biblos, 1995), p. 73.

${ }^{48}$ Una nueva explicación del mismo autor sobre las lecturas incorrectas de Geertz en: Muñoz, Santiago y Pérez, María Cristina, Op Cit., p. 201.

${ }^{49}$ Para un análisis de los postulados de esta visión de la cultura: Geertz, Clifford. "Descripción densa: hacia una teoría interpretativa de la cultura", en Geertz, Clifford, La interpretación de las culturas (Barcelona: Editorial Gedisa, 2003), pp. 19-40.

${ }^{50}$ Levi, Giovanni, Op Cit., p. 77.

${ }^{51}$ Ibid.

${ }^{52}$ Levi, Giovanni. "Sobre microhistoria", en Burke, Peter (ed.), Formas de hacer Historia (Madrid: Alianza Editorial, 1999), pp. 119-143; Levi, Giovanni. "Un problema de escala", en Relaciones. Estudios de historia y sociedad, vol. XXIV, núm. 95, 2003, pp. 279-288.

${ }^{53}$ Vale recordar, en este punto, el llamado de atención de Carlo Ginzburg en su propuesta de la circularidad para explicar la relación entre élites y subalternos. Este recomienda la lectura de fuentes diversas para evitar los dados cargados; acceder con los documentos tradicionales llevaría a exagerar el peso de la cultura dominante, lo que bien puede equivaler a trabajar con un contexto inmóvil y jerárquico donde los flujos van de arriba hacia abajo como si fuera un molde en el cual hacer casar las experiencias singulares. Ginzburg, Carlo. El queso..., p. 232.
} 
mejor lo afirmado al respecto por Levi es necesario ir a su trabajo más reconocido; allí el autor parte de una incomodidad frente a aquellas opiniones que muestran a la sociedad del antiguo régimen como un mundo estático, incapaz de iniciativas autónomas ${ }^{54}$. De ahí su afirmación: "Los modelos construidos por los historiadores y antropólogos se han servido (lo que quizá sea inevitable) de definiciones que intentan aunar los comportamientos bajo una única ley explicativa, a menudo oscilando entre una caracterización rica y articulada, pero inmóvil, de la cultura de las clases populares y un cuadro desarticulado, sin defensas por el atraso mismo de los principios económicos y sociales" ${ }^{\prime 5}$. En ese sentido Levi propone estudiar una fase de un conflicto, en el que salen transformados tanto el poder central como la sociedad local. Generalmente, siguiendo al autor, se observa de lejos la sociedad para ver que los resultados finales a menudo "exceden la posibilidad de control de las personas" 56 , y por ello las resistencias parecen insignificantes o históricamente irrelevantes; pero realmente "[...] en los intersticios de los sistemas normativos estables o en formación, grupos y personas juegan una estrategia propia y significativa, capaz de marcar la realidad política con una huella duradera, no de impedir las formas de dominación sino de condicionarlas y modificarlas" ${ }^{\prime 57}$.

Levi cuestiona la mecanización de las relaciones entre individuo y normas, entre decisión y acción, y propone sus categorías interpretativas: la ambigüedad de las reglas; la necesidad de tomar decisiones conscientemente en medio de la incertidumbre; la consciente utilización de las incoherencias entre sistemas de reglas y sanciones. Estas categorías no son obstáculos para considerar a una sociedad como activa, y al sistema social como "[...] resultado de la interacción entre comportamientos y decisiones tomadas en el marco de una racionalidad plena, pero limitada" 58 . Lo que Levi intenta leer en el caso de Giovan Battista Chiesa son las motivaciones y las estrategias de la acción política: "[...] la legitimidad política de un mediador local se funda, de esta manera, en un frágil equilibrio de intereses irreconciliables, de perspectivas inciertas y de prestigio personal" 59 . Frente a los problemas que surgen en las transformaciones históricas, las creencias y las ideologías, las relaciones de dominio y de autoridad, el autor intenta describir "[...] la inestabilidad de las preferencias individuales, los órdenes institucionales, las jerarquías y los valores sociales: en suma, el proceso político, que genera el cambio, pero también sus direcciones imprevisibles fruto del encuentro de protagonistas activos" ${ }^{" 60}$.

Cuando se habla de significación o simbolismo, partiendo de una imagen circular en la que el contexto precede a los casos singulares y los ordena, existiría el riesgo de dar

\footnotetext{
${ }^{54}$ Levi, Giovanni. La herencia inmaterial. La historia de un exorcista piamontés del siglo XVII (Madrid: Nerea, 1985).

${ }^{55}$ Ibid., p. 10.

${ }^{56}$ Ibid., p. 11.

${ }^{57}$ Ibid.

${ }^{58}$ Ibid., p. 12.

${ }^{59}$ Ibid., p. 14.

${ }^{60}$ Ibid., p. 15.
} 
una imagen paralizante de los hombres en sociedad ${ }^{61}$. Generalmente se intenta explicar la norma como si produjera algo definido y singular, cuando -al contrario- los códigos normativos generan un amplio abanico de posibilidades, esa pluralidad es la que les va a interesar a Levi y a Thompson ${ }^{62}$. Y no es que estos dos autores desconozcan los límites de la libertad del hombre, que no vean las imposiciones y las normas establecidas, sino que, al contrario, construyen una imagen compleja y dinámica de las mismas; lo que se puede asimilar con lo señalado por Ginzburg: "Como la lengua, la cultura ofrece al individuo un horizonte de posibilidades latentes, una jaula flexible e invisible para ejercer dentro de ella la propia libertad condicionada" ${ }^{93}$.

Edward Palmer Thompson, por su parte, ha logrado romper a su manera con el esquematismo que surge en ciertas obras dedicadas al estudio de la cultura. Aunque comparte con Levi la cercanía por la propuesta de la antropología simbólica, llama la atención sobre los desaciertos que pueden emerger tras una aplicación demasiado burda de explicaciones estructurales y esquemáticas ${ }^{64}$. Así, por ejemplo, en su artículo sobre la economía moral en el siglo XVIII, se enfrenta a una visión peyorativa de la historia de las multitudes, visión quizás entendible por los cerrados espacios de reflexión que aportan enfoques demasiado estructurales. El desprecio a la acción de la multitud provendría de un reduccionismo que ignora "motivación, conducta y función", sería el resultado de aquellas perspectivas esquemáticas que frenan la investigación en el punto exacto donde cobra interés ${ }^{65}$. Es en este sentido que, en el análisis de los motines en la Inglaterra del siglo XVIII, el autor distingue "el ideal platónico de la ley" de "las embarazosas realidades" del consumo y el comercio. Bajo el objetivo de ampliar las imágenes de las acciones de la multitud, Thompson logra mostrar la capacidad de acción de la multitud británica del siglo XVIII, definiéndose esta como un "modelo de protesta social" derivado de un consenso ${ }^{66}$.

Ese modelo de comportamiento, no obstante, es entendido por el mismo Thompson como un apoyo provisional, pues entiende que categorías y modelos derivados de un contexto deben ponerse a prueba y reajustarse en el curso de la investigación histórica ${ }^{67}$. El historiador británico consigue llamar la atención sobre la provisionalidad de las herramientas con las que trabaja el historiador, lo que para White eran recursos literarios y para Ginzburg pruebas sólidas en el marco de la retórica aristotélica, para

\footnotetext{
61 "Quedarse en la norma es lo mismo que quedarse en el símbolo; los historiadores debemos ir más allá y estudiar su relación con los comportamientos y las prácticas sociales”: Muñoz, Santiago y Pérez, María Cristina, Op Cit., p. 201.

${ }^{62}$ Para un análisis de la obra más reconocida de Thompson: Kaye, Harvey. "E.P. Thompson: La formación de la clase trabajadora inglesa", en Kaye, Harvey, Los historiadores marxistas británicos. Un análisis introductorio (Zaragoza: Universidad de Zaragoza, 1989), pp. 153-198.

${ }^{63}$ Ginzburg, Carlo. El queso..., p. 22.

${ }^{64}$ Thompson, Edward. “Agenda para una historia radical”, en Agenda para una historia radical (Barcelona: Crítica, 2000), pp. 8-43

${ }^{65}$ Thompson, Edward. "La economía 'moral' de la multitud”, en Thompson, Edward, Costumbres en Común (Barcelona: Crítica, 1995), pp. 213-293.

${ }^{66}$ Ibid., p. 279.

${ }^{67}$ Thompson, Edward. “Agenda para una historia radical”... Op Cit., p. 16.
} 
Thompson van a aparecer como evidencias documentales - más cercano a Ginzburg que a White, evidentemente- que se ponen en diálogo mediante los conocimientos de un contexto, los cuales nunca son estáticos ni definitivos. Como ningún modelo, ni ninguna estructura, ni ninguna trama deben preexistir coercitivamente a la investigación del historiador, se abre una posibilidad para dejar atrás el enfoque obsesivo y desmesurado por aparatos impersonales (estructuras económicas, modelos de comportamiento, etc.) para dar paso a una visión que privilegia la posibilidad de acción de los hombres, capaces de transformar las estructuras de su entorno.

Esta última visión puede encontrarse en las obras de Levi y Thompson, pero lo que marca la diferencia entre ambos, sin distanciarlos radicalmente, es su aproximación temática; mientras que el italiano se ha preocupado por historiar los intersticios en los que nacen las acciones de los individuos, el británico ha optado por detenerse en aquellos procesos que develan la capacidad de consenso y acción de la multitud ${ }^{68}$. Ambos autores han buscado llamar la atención sobre la complejidad de los procesos históricos, tomando para su observación los conflictos sociales, pero fundamentalmente desde la comprensión de las márgenes de libertad que poseen las expresiones humanas, así como el potencial de transformación que subyace en las decisiones y las prácticas de los hombres ${ }^{69}$. Ya sea una multitud cambiante, como los amotinados en la Inglaterra del siglo XVIII, o un individuo particular, como el exorcista piamontés, el énfasis se pone en el carácter accidentado y fragmentario de la realidad, en lo dudoso de las fórmulas de poder que parecen muy lineales, en la ineficacia de las estructuras o modelos de comportamiento que aparecen como demasiado estrechos y simplistas.

Frente a códigos y normas, expresiones de autoridad que en toda sociedad dan la sensación de unidad y cohesión, Levi y Thompson plantean la pluralidad que introducen los sujetos históricos: que son capaces de ubicarse comprensivamente en su contexto y agenciar resistencias o consensos frente a las formas de poder, siempre coactivas desde su potencialidad, pero muchas veces erráticas en la práctica. Encontramos entonces, al igual que en Ginzburg, la conciencia de la necesidad de alternar las grandes miradas macroscópicas con las observaciones detallistas, un ir y venir entre el contexto histórico, las estructuras, las acciones de los hombres y sus resultados ${ }^{70}$. La escritura de ambos autores es diferente, y allí quizás sus caminos se

\footnotetext{
${ }^{68}$ León, Paulo. "El discurso intelectual de E.P. Thompson", en Anuario Colombiano de Historia Social y de la Cultura, núm. 33, Bogotá, Universidad Nacional de Colombia, 2006, pp. 337-364.

${ }^{69}$ Puede establecerse un vínculo entre estos autores y Pierre Vilar; este último recuerda que pensar históricamente exige una ponderación de innovaciones y herencias: Vilar, Pierre. "Pensar históricamente", en Vilar, Pierre, Memoria, Historia e historiadores (Granada: Universidad de Granada-Universidad de Valencia, 2004), pp. 67-122.

${ }^{70}$ Fernand Braudel ya habría recalcado la importancia de usar las nociones de estructura, modelo y regularidad sociales, acudiendo a la sociología; Hobsbawm, por su parte, habría afirmado que la historia de la sociedad es una colaboración entre modelos generales, estructura, cambio, y un conjunto de fenómenos específicos que ocurrieron. Lo anterior es recordado por Renán Silva, quien sugiere ampliar estas ideas y dice que para acudir a los modelos, estos deben combinarse con el uso de escalas micro y de análisis concentrados, así como con "[...] el examen de los casos límite, de los bordes y de los reversos sociales", y con el "[...] uso de la biografía como forma de análisis de la sociedad y de las formas históricas de la individualidad": Silva, Renán. "Sobre sociología e historia”, en Silva, Renán, A la sombra de Clío: diez
} 
bifurcan un poco: Levi está un poco más cercano a un ejercicio narrativo como el de Ginzburg, mientras que Thompson posee un estilo más analítico; no obstante, si recordamos su punto de partida -la posibilidad de transformación potencial en las actividades humanas-, no es difícil aceptar que son más los puntos que los unen que los que los separan.

\section{Consideraciones finales}

El estructuralismo, que se erigió desde mediados de siglo XX como un requerimiento para que las ciencias sociales alcanzaran un estatuto de validez como el de las ciencias naturales, exigía un detenimiento en el tratamiento de las abstracciones impersonales, ese sería el precio exigido para superar el legado y la mala fama que dejaría la historia tradicional del siglo $\mathrm{XIX}^{71}$. Desde mediados de siglo XX surgieron propuestas que se apartaban del pesado requisito del estructuralismo más riguroso; no como una negación de la existencia de estructuras sino como una humanización de las mismas. Ya a finales del siglo pasado, acudiendo a los elementos narrativos y lingüísticos, planteamientos como los de White y Ginzburg revitalizaron las discusiones y orientaciones sobre la escritura histórica. Levi y Thompson, no ajenos a este debate, introdujeron preguntas y respuestas sobre el margen de libertad que habita en las prácticas humanas; sobre los intersticios en las estructuras e instituciones de poder, y sobre la capacidad de impacto y resistencia de los grupos sociales. Esos márgenes de acción que poseen individuos y multitud son también limitados por las condiciones de existencia del grupo social; pues no se trata de una negación radical del poder y la autoridad. Hay también una coincidencia implícita y sumamente interesante: en la obra de Thompson y Levi se asume que el margen de interpretación está dado por el trabajo empírico con las fuentes documentales, y que más allá de ellas no se puede sostener o discutir, siempre y cuando no sea con un reposado y coherente ejercicio de imaginación histórica.

Proponemos que existe una cercanía considerable entre las propuestas de los historiadores hasta acá abordados, cuyos trabajos constituyen verdaderos ensayos de definición del campo disciplinar de los estudios históricos. No hemos buscado un estudio sistemático de estos autores, o un análisis especializado de sus respectivas obras; ponemos sobre la mesa, más bien, una mirada inicial a algunos de sus postulados, en relación a un contexto disciplinar relativamente cercano e indiscutiblemente vigente. La cuestión de la capacidad de acción de la multitud y los individuos en los intersticios de las estructuras, ha sido un lugar visitado desde la academia anglosajona y los autores de la microhistoria italiana; con la elaboración singular que cada historiador emprende de esta constante, se llega a una delimitación de los objetivos

ensayos sobre historia e historiografia (Medellín: La Carreta Editores, 2007), pp. 17-42. Esta no es la idea exacta de contexto en la microhistoria, pero propone una integración interesante de posturas que pueden ser ponderadas para un acercamiento a la obra de los autores analizados en este artículo.

${ }^{71}$ Mala fama que es una invención, pues la crítica histórica decimonónica ha aportado elementos que incluso hoy se mantienen vigentes; Leopold Von Ranke, y otros autores, fueron caricaturizados injustamente durante la creación de un nuevo canon historiográfico en el segundo cuarto del siglo XX. 
de la Historia, que no constituye como tal una teoría esquemática y auto-contenida, siendo esto precisamente lo que discuten y enfrentan; más bien, sus esfuerzos apuntan al planteamiento de unos itinerarios plausibles para la construcción de una disciplina histórica capaz de construir un conocimiento amplio, sólido y reflexivo sobre el pasado de los hombres en sociedad, sin renunciar a su cercanía con el arte y la literatura ${ }^{72}$. Finalmente, creemos que esos intersticios, que de una u otra manera han ocupado un lugar prominente en la obra de historiadores contemporáneos, pueden ser entendidos como espacios para la acción; la consciencia de la provisionalidad de los alcances de la historiografía permite que se pueda encontrar un justo medio entre los placeres de la imaginación narrativa y el rigor de las evidencias documentales.

\section{Fuentes}

\section{Fuentes primarias}

\section{Libros}

Ginzburg, Carlo. El queso y los gusanos. El cosmos según un molinero del siglo XVI. Barcelona: Muchnik Editores, 1981.

Levi, Giovanni. La herencia inmaterial. La historia de un exorcista piamontés del siglo XVII. Madrid: Nerea, 1985.

\section{Capítulos de libros}

Ginzburg, Carlo. “Apéndice. Pruebas y posibilidades”, en Ginzburg, Carlo, El Hilo y las Huellas: Lo verdadero, lo falso, lo ficticio. Buenos Aires: Fondo de Cultura Económica, 2010.

Ginzburg, Carlo. "Descripción y Cita”, en Ginzburg, Carlo, El Hilo y las Huellas: Lo verdadero, lo falso, lo ficticio. Buenos Aires: Fondo de Cultura Económica, 2010.

Ginzburg, Carlo. "Microhistoria dos o tres cosas que sé de ella", en Ginzburg, Carlo, El Hilo y las Huellas: Lo verdadero, lo falso, lo ficticio. Buenos Aires: Fondo de Cultura Económica, 2010.

\footnotetext{
${ }^{72}$ No se trata, entonces, de una postura meramente empírica o anti-teórica. Al respecto es interesante retomar una afirmación reciente y extremadamente aguda: "El historiador requiere de teorías para descubrir las experiencias del pasado. No obstante, la narración implica un acto de recuerdo, lo que conlleva a una reproducción o un relato del relato bajo las premisas de quien interpreta, por ello en su labor narrativa se reflejan o confluyen sus propias experiencias. El historiador puede salirse del campo meramente lingüístico que las fuentes le ofrecen, pues los conceptos aducen la representación de una unidad de acción que orienta los factores y los límites de los conceptos como tal. En su interpretación tematiza y recrea un estado de cosas desde la indicación testimonial de los textos y las cuestiones o preguntas realizadas a estos". Uribe, Marcela. "Tiempo histórico y representación en la Histórica de Reinhart Koselleck", en Anuario Colombiano de Historia Social y de la Cultura, vol. XLIII, núm. 1, Bogotá, Universidad Nacional de Colombia, 2016, pp. 358 y 359.
} 
Ginzburg, Carlo. "Huellas. Raíces de un paradigma indiciario", en Ginzburg, Carlo, Tentativas. Morelia: Universidad Michoacana de San Nicolás de Hidalgo, 2003.

Ginzburg, Carlo. "Acerca de la historia local y la microhistoria”, en Ginzburg, Carlo, Tentativas. Morelia: Universidad Michoacana de San Nicolás de Hidalgo, 2003.

Levi, Giovanni. "Los peligros de geertzismo", en Hourcade, Eduardo; Godoy, Cristina y Botalla, Horacio, Luz y Contraluz de una Historia Antropológica. Buenos Aires: Biblos, 1995.

Levi, Giovanni. "Sobre microhistoria", en Burke, Peter (ed.), Formas de hacer Historia. Madrid: Alianza Editorial, 1999.

Thompson, Edward. "Agenda para una historia radical", en Agenda para una historia radical. Barcelona, Crítica, 2000.

Thompson, Edward. "La venta de esposas", en Costumbres en Común. Barcelona: Crítica, 1995.

Thompson, Edward. "La cencerrada", en Costumbres en Común. Barcelona: Crítica, 1995.

Thompson, Edward. "La economía 'moral' de la multitud", en Costumbres en Común. Barcelona: Crítica, 1995.

White, Hayden. "El texto histórico como artefacto literario", en White, Hayden, El texto histórico como artefacto literario. Barcelona: Paidós, 2003.

White, Hayden. "La poética de la historia", en White, Hayden, Metahistoria: La imaginación histórica en la Europa del siglo XIX. México: Fondo de Cultura Económica, 2000.

\section{Artículos en revista}

Ginzburg, Carlo. "Historia, retórica, prueba. Sobre Aristóteles y la historia hoy", en Entrepasados, núm. 27, 2005.

Levi, Giovanni. "Un problema de escala", en Relaciones. Estudios de historia y sociedad, vol. XXIV, núm. 95, 2003.

\section{Fuentes secundarias}

\section{Libros}

Bloch, Marc. Introducción a la Historia. México: Fondo de Cultura Económica, 1979. 
Los espacios para la acción. Intersticios y tramas en la construcción del relato...

Braudel, Fernand. La historia y las ciencias sociales. Madrid: Alianza Editorial, 1970. Chartier, Roger. La historia o la lectura del tiempo. Barcelona: Editorial Gedisa, 2007.

Certeau, Michel de. La escritura de la historia. México: Universidad Iberoamericana, 1999.

Darnton, Robert. La gran matanza de gatos y otros episodios en la historia de la cultura francesa. México: Fondo de Cultura Económica, 1987.

Febvre, Lucien. Combates por la historia. Barcelona: Ariel, 1974.

Illades, Carlos. Breve introducción al pensamiento de E. P. Thompson. México: Universidad Autónoma Metropolitana, 2008.

LeGoff, Jacques. ¿Realmente es necesario cortar la historia en rebanadas? México: Fondo de Cultura Económica, 2016.

Marx, Karl. El 18 brumario de Luis Bonaparte. Madrid: Fundación Federico Engels, 2003.

Ricoeur, Paul. Teoría de la interpretación. Discurso y excedente de sentido. México: Siglo Veintiuno Editores, 2006.

\section{Capítulos de libros}

Aróstegui, Julio. "La renovación contemporánea de la historiografía", en Aróstegui, Julio, La Investigación Histórica: Teoría y Método. Madrid: Crítica, 1995.

Aurell, Jaume. "El giro narrativo", en Aurell, Jaume, La escritura de la memoria: de los positivismos a los posmodernismos. Valencia: Universitat de Valencia, 2005.

Aurell, Jaume. "La transición de los setentas: de las economías a las mentalidades", en Aurell, Jaume, La escritura de la memoria: de los positivismos a los posmodernismos. Valencia: Universitat de Valencia, 2005.

Chaves, María Eugenia. "La pregunta y el indicio. A propósito del trabajo sobre fuentes judiciales y casos particulares en la investigación histórica sobre los sectores subalternos", en Almario Oscar (ed.), Las fuentes en las reflexiones sobre el pasado: usos y contextos en la investigación histórica en Colombia. Medellín: Universidad Nacional de Colombia, 2014.

Geertz, Clifford. "Descripción densa: hacia una teoría interpretativa de la cultura", en Geertz, Clifford, La interpretación de las culturas. Barcelona: Editorial Gedisa, 2003. 
Kaye, Harvey. "E.P. Thompson: La formación de la clase trabajadora inglesa", en Kaye, Harvey, Los historiadores marxistas británicos. Un análisis introductorio. Zaragoza: Universidad de Zaragoza, 1989.

Silva, Renán. "Sobre sociología e historia”, en Silva, Renán, A la sombra de Clío: diez ensayos sobre historia e historiografía. Medellín: La Carreta Editores, 2007.

Vilar, Pierre. "Pensar históricamente", en Vilar, Pierre, Memoria, Historia e historiadores. Granada: Universidad de Granada-Universidad de Valencia, 2004.

\section{Artículos en revista}

Barrios, Carlos. "La contribución de los Annales y la historia de las mentalidades. 1969-1989”, en Iztapalapa, Revista de Ciencias Sociales y Humanas, núm. 36, 1995.

Bourdieu, Pierre. “La ilusión biográfica”, en Acta Sociológica, núm. 56, 2011.

Chartier, Roger. "La historia, entre relato y conocimiento", en Historia y Espacio, núm. 17, 2001.

Chaves, María Eugenia. "Presentación. Reflexiones sobre la Microhistoria italiana: conceptos, método y estudio de casos", en Historia y Sociedad, núm. 30, 2016.

Hobsbawm, Eric. "The Revival of Narrative: Some Comments", en Past \& Present, núm. 86, 1980.

León, Paulo. "El discurso intelectual de E.P. Thompson", en Anuario Colombiano de Historia Social y de la Cultura, núm. 33, 2006.

Muñoz, Santiago y Pérez, María Cristina. "Perspectivas historiográficas: entrevista con el profesor Giovanni Levi”, en Historia Crítica, núm. 40, 2010.

Satlari, María Cristina. "La historia en los debates de la posmodernidad", en Cuyo. Anuario de Filosofía Argentina y Americana, núm. 24, 2007.

Uribe, Marcela. "Tiempo histórico y representación en la Histórica de Reinhart Koselleck", en Anuario Colombiano de Historia Social y de la Cultura, vol. XLIII, núm. 1, 2016.

\section{Publicaciones en Internet}

Serna, Justo, y Pons, Anaclet. “Anti White”, en Serna, Justo, y Pons, Anaclet, Cómo se escribe la microhistoria. Ensayo sobre Carlo Ginzburg, http://www.uv.es/jserna/ AntiWhite. 